\title{
Evaluation of the surface free energy of plant surfaces: toward standardizing the procedure
}

\author{
Victoria Fernández ${ }^{1 *}$ and Mohamed Khayet ${ }^{2,3 *}$ \\ ${ }^{1}$ Forest Genetics and Ecophysiology Research Group, Plant Physiology and Anatomy Unit, School of Forest Engineering, \\ Technical University of Madrid, Madrid, Spain, ${ }^{2}$ Department of Applied Physics I, Faculty of Physics, Complutense University \\ of Madrid, Madrid, Spain, ${ }^{3}$ Madrid Institute for Advanced Studies of Water (IMDEA Water Institute), Madrid, Spain
}

\section{OPEN ACCESS}

Edited by:

Michael Knoblauch,

Washington State University, USA

Reviewed by:

Kaare Hartvig Jensen,

Harvard University, USA

Eric M. Kramer,

Bard College at Simon's Rock, USA

*Correspondence:

Victoria Fernández,

Forest Genetics and Ecophysiology Research Group, Plant Physiology and Anatomy Unit, School of Forest Engineering, Technical University of Madrid, Ciudad Universitaria s/n, 28040 Madrid, Spain

v.fernandez@upm.es;

victoria.fernandez@gmx.de;

Mohamed Khayet,

Department of Applied Physics I, Faculty of Physics, Complutense

University of Madrid, Avda. Complutense s/n, 28040 Madrid,

Spain

khayetm@fis.ucm.es

Specialty section:

This article was submitted to

Plant Biophysics and Modeling, a section of the journal Frontiers in Plant Science

Received: 26 March 2015 Accepted: 25 June 2015 Published: 07 July 2015

Citation:

Fernández V and Khayet M (2015) Evaluation of the surface free energy of plant surfaces: toward standardizing the procedure. Front. Plant Sci. 6:510. doi: $10.3389 / \mathrm{fp} / \mathrm{s} .2015 .00510$
Plant surfaces have been found to have a major chemical and physical heterogeneity and play a key protecting role against multiple stress factors. During the last decade, there is a raising interest in examining plant surface properties for the development of biomimetic materials. Contact angle measurement of different liquids is a common tool for characterizing synthetic materials, which is just beginning to be applied to plant surfaces. However, some studies performed with polymers and other materials showed that for the same surface, different surface free energy values may be obtained depending on the number and nature of the test liquids analyzed, materials' properties, and surface free energy calculation methods employed. For 3 rough and 3 rather smooth plant materials, we calculated their surface free energy using 2 or 3 test liquids and 3 different calculation methods. Regardless of the degree of surface roughness, the methods based on 2 test liquids often led to the under- or over-estimation of surface free energies as compared to the results derived from the 3-Liquids method. Given the major chemical and structural diversity of plant surfaces, it is concluded that 3 different liquids must be considered for characterizing materials of unknown physico-chemical properties, which may significantly differ in terms of polar and dispersive interactions. Since there are just few surface free energy data of plant surfaces with the aim of standardizing the calculation procedure and interpretation of the results among for instance, different species, organs, or phenological states, we suggest the use of 3 liquids and the mean surface tension values provided in this study.

Keywords: contact angles, cuticle, geometric mean, plant surfaces, surface free energy, three-liquids method

\section{Introduction}

Plant surfaces play a crucial role in protecting organs against an array of biotic and abiotic stress factors (Riederer, 2006). For instance, they may serve as barrier for the attack of pests and pathogens (Eigenbrode and Jetter, 2002; Serrano et al., 2014), high UV and visible radiation intensities (Reicosky and Hanover, 1978; Karabourniotis and Bormann, 1999), and chiefly the uncontrolled loss of water (Riederer and Schreiber, 2001). On the other hand, plant surface permeability to liquids may be a phenomenon of ecophysological and agronomic significance since it may enable the absorption of, for example, liquid water (Oliveira et al., 2005; Fernández et al., 2014a), fog (Limm and Dawson, 2010; Eller et al., 2013; Berry et al., 2014), dew 
(Konrad et al., 2012), foliar fertilizers (Fernández and Eichert, 2009; Fernández and Brown, 2013) or biostimulants (Saa et al., 2015). This will be first influenced by the wettability and adhesion or repellence of water drops onto plant surfaces (Fernández et al., 2014a).

Most aerial plant organs are protected by epidermal cells (including stomata and/or trichomes) of different shapes and sizes (Javelle et al., 2011; Fernández and Brown, 2013). The epidermis itself is covered with a cuticle, a layer which may be interpreted as a lipidized area of the epidermal cell wall (Guzmán et al., 2014). The outermost surface of the cuticle is the epicuticular wax layer, which may present a major degree of variability depending on the chemical and structural nature of epicuticular waxes (Barthlott et al., 1998; Jetter et al., 2006), and may also be affected by the prevailing environmental conditions during plant growth (Jeffree et al., 1975; Shepherd and Wynne Griffiths, 2006). Depending on the micro- and nanostructure of epidermal cells, epicuticular waxes and cuticular folds, plant surfaces may have different degrees of roughness and water drop repellence or adhesion (Koch and Barthlott, 2009; Fernández et al., 2014a). During the last decade and in light of the major plant surface variability observed by scanning electron microscopy (SEM) (Barthlott et al., 1998), there is a rising interest in examining plant surface topography and performance when in contact with water drops for the development of bio-mimetic materials (Bhushan and Jung, 2010). The existing epidermal micro-and nano-surface features together with surface chemical composition (Khayet and Fernández, 2012) will determine the degree of plant surface roughness and hydrophobicity (Fernández et al., 2014a).

Despite the fact that the mechanisms of foliar uptake of water and solutes by plant surfaces are still not fully understood (Fernández and Eichert, 2009; Burkhardt and Hunsche, 2013), several studies analyzed the interactions of plant surfaces with water (Brewer et al., 1991; Brewer and Smith, 1997; Hanba et al., 2004; Brewer and Nuñez, 2007; Dietz et al., 2007; RothNebelsick et al., 2012; Rosado and Holder, 2013; Urrego-Pereira et al., 2013; Wang et al., 2014). Such investigations largely focussed on analysing the wettability and hydrophobicity of plant surfaces based on water contact angles. However, Fernández et al. (2011, 2014a) and Khayet and Fernández (2012) suggested the implementation of membrane science approaches for analysing the physico-chemical properties of plant surfaces and introduced surface free energy results derived from the measurement of contact angles of 3 liquids with different degrees of dispersive and non-dispersive interactions according to the method of Van Oss et al. $(1987,1988)$.

The surface tensions of the interfaces of a solid with liquids and the surrounding vapors are key parameters, which are commonly applied for characterizing the physico-chemical properties of surfaces in many areas of applied science and technology (Correia et al., 1997). The theory of interfacial tensions $(\gamma)$ and surface free energy (SFE) was first introduced by Young (1805). Subsequently, several theoretical approaches were developed between the 1950's and the 1980's (e.g., Fox and Zisman, 1950; Girifalco and Good, 1957; Fowkes, 1964; Owens and Wendt, 1969; Wu, 1971; Good, 1977; Van Oss et al., 1986,
1988) with the aim of estimating solid surface tension $\left(\gamma_{s}\right)$ or $S F E$ which is the same) from contact angles of 2 or 3 liquids with different dispersive and non-dispersive components.

Despite the interest in estimating the SFE of different solids ranging from polymers and co-polymer blends (e.g., Correia et al., 1997; Adão et al., 1999), to polymeric membranes (Khayet et al., 2003, 2007), geological materials (Chibowski and Staszczuk, 1988; Helmy et al., 2004), or wood (Gindl et al., 2001), there is a fair degree of controversy concerning several associated aspects such as the liquid surface tension and contact angle determination methods, the use of 2, 3 or more test liquids and the different calculation methods reported (Morra, 1996; Della Volpe and Siboni, 1997; Jañczuk et al., 1999; Kwok and Neumann, 1999; Tretinnikov, 2000; Chibowski and PereaCarpio, 2002; Della Volpe et al., 2004).

Since there are still few SFE data of plant materials (Gorb et al., 2004; Fernández et al., 2011, 2014a,b; Khayet and Fernández, 2012; Wang et al., 2014), and current contact angle measuring devices are available with software enabling: (i) the direct estimation of the SFE of solids and their components according to different methods, and (ii) the selection of different test liquid surface tension values, we carried out preliminary efforts to revise the existing SFE theory together with the most commonly used SFE determination methods, and to calculate the mean values for the total surface tension and surface tension components of water $(W)$, glycerol $(G)$ and diiodomethane (DM), which have been often used for such purpose. It must be stressed that SFE estimations of a solid surface by contact angle measurements of either 2 or 3 test liquids of the same nature should be similar or at least within the same range as reported in several studies performed with some synthetic materials (e.g., Adão et al., 1999; Khayet et al., 2003). However, the major structural (roughness) and chemical (polarity, apolarity and hydrogenbonding interactions) variation observed among plant species, organs or organ parts made us develop trials to calculate the SFE of model plant surfaces when measured with the most commonly used SFE estimation methods, which employ either 2 or 3 test liquids. With the aim of choosing a procedure for determining the $S F E$ of plant materials to be systematically used in future research attempts, we further calculated this parameter using contact angle measurements of either pairs of liquids (i.e., W-DM, G$\mathrm{DM}, \mathrm{W}-\mathrm{G}$ ) considering both the geometric and harmonic mean approaches, or 3 liquids (W-G-DM) applying the Lifshitz-van der Waals-acid-base or van Oss, Good and Chaudhury method (Van Oss et al., 1986, 1987, 1988). The contact angles of W, G and DM were determined on to 3 rough and 3 rather flat model plant surfaces and the SFE obtained by different methods were compared.

\section{Materials and Methods}

\section{Plant Material}

The plant materials analyzed as model correspond to intact, mature red ironbark (Eucalyptus sideroxylon A. Cunn. ex Woolls) leaves, juvenile blue gum eucalypt (Eucalyptus globulus Labill.) leaves, mature Chilean myrtle (Luma apiculata (DC.) Burret) leaves, mature rubber tree (Ficus elastica Roxb. ex 
Hornem) leaves, mature holm-oak (Quercus ilex subsp. ballota (Desf.) Samp.) leaves, and red bell peppers (Capsicum annum L. cv. "Genil"). Rubber tree and Chilean myrtle leaves and also pepper fruit surfaces are smooth while red iron bark, blue gum eucalypt and holm oak leaf surfaces are extremely rough. We examined the properties of the upper leaf side of red ironbark blue gum eucalypt, Chilean myrtle, and rubber tree. The lower leaf side of holm-oak and the pepper fruit surface were also analyzed.

\section{Scanning Electron Microscopy}

Gold sputtered plant materials were examined with a Hitachi S-3400 N (Tokyo, Japan) and a Philips XL30 (Eindhoven, The Netherlands) scanning electron microscope (SEM).

\section{Contact Angle Measurements}

The test liquids analyzed were double-distilled water (W), glycerol (G) and diiodomethane (DM, both $99 \%$ purity, SigmaAldrich). Advancing contact angles of drops of such liquids were measured at $20^{\circ} \mathrm{C}$ using a contact angle meter CAM 200 (KSV Instruments Ltd., Helsinki, Finland). Drops of each liquid were deposited on to intact plant surfaces (30 repetitions) with a manual dosing system holding a $1 \mathrm{~mL}$ syringe $(0.5 \mathrm{~mm}$ diameter needle). Side view images of the drops were captured at a rate of 10 frames $\mathrm{s}^{-1}$. Contact angles were automatically calculated by fitting the captured drop shape to the one calculated from the Young-Laplace equation.

\section{Surface Free Energy Calculation Methods}

Since the total SFE, $\gamma_{s}$, cannot be calculated directly (Khayet et al., 2003), different indirect methods have been proposed which based on the contact angle measurement of either 2 or 3 different liquids deposited on to a solid surface (Jañczuk and Białlopiotrowicz, 1989; Della Volpe and Siboni, 1997). Three calculation methods were used for estimating $\gamma_{s}$, its components and the resulting solubility parameter $(\delta)$ of different plant materials. Provided that we observed a significant dispersion of the total surface tension and surface tension component data provided in the literature for various liquids including $\mathrm{W}, \mathrm{G}$ and $\mathrm{DM}$, the mean values of all results gathered were considered in this study (Table 1).

\section{Calculations Based on 2 Liquids}

The 2-liquid based, geometric mean and harmonic mean methods of calculation of SFE are commonly used for characterizing synthetic surfaces (e.g., Correia et al., 1997; Adão et al., 1999) and have been used in this investigation.

Based on the theory of Girifalco and Good (1957), Fowkes $(1962,1964)$ proposed that $\gamma_{s}$ (SFE of the solid to be analyzed) is the sum of contributions from the different intramolecular forces at the surface: those due to dispersion interactions, dipoledipole interactions, dipole induced-dipole interactions, hydrogen bonding, $\Pi$-bonding, electrostatic interactions and acceptordonor interactions.

For simplicity, $\gamma_{s}$ ca be expressed as the sum of dispersive $\left(\gamma_{s}^{d}\right)$ and non-dispersive $\left(\gamma_{s}^{\text {nd }}\right)$ interactions (Jañczuk et al., 1989; Kwok et al., 1994):

$$
\gamma_{s}=\gamma_{s}^{d}+\gamma_{s}^{n d}
$$

While there is agreement in the nomenclature for the dispersive SFE component $\left(\gamma_{s}^{d}\right)$, many authors referred to the remaining term (i.e., $\gamma_{s}^{\text {nd }}$ ), which obviously includes many types of forces (Fowkes, 1964), as polar component $\gamma_{s}^{p}$ (e.g., Wu, 1971). To avoid any possible misinterpretation, we will subsequently refer to the $\gamma_{s}^{d}$ and $\gamma_{s}^{\text {nd }}$ components throughout the manuscript.

\section{Geometric Mean Method}

Based on Fowkes' assumption that dispersive interactions between the molecules of the solid and the liquid prevailed among other acting forces, and considering Young's equation, the following expression was suggested (Fowkes, 1964):

$$
2 \sqrt{\gamma_{s}^{d} \gamma_{l}^{d}}=\gamma_{l}(1+\cos \theta)
$$

where, $\gamma_{l}$ is the total surface tension of the liquid, $\gamma_{l}^{d}$ is the dispersive component of the liquid and $\theta$ is the contact angle measured between the liquid and the solid under study.

This equation was further expanded by Owens and Wendt (1969) to:

$$
2 \sqrt{\gamma_{s}^{d} \gamma_{l}^{d}}+2 \sqrt{\gamma_{s}^{n d} \gamma_{l}^{n d}}=\gamma_{l}(1+\cos \theta)
$$

\begin{tabular}{|c|c|c|c|c|c|c|}
\hline \multirow[b]{2}{*}{ Liquid } & \multirow[b]{2}{*}{$\gamma_{I}\left(\mathrm{~mJ} \mathrm{~m}^{-2}\right)$} & \multicolumn{2}{|c|}{$\begin{array}{c}\text { Liquid } \gamma \text { components) } \\
\text { for } \mathrm{GM} \text { and } \mathrm{HM} \text { methods }\left(\mathrm{mJ} \mathrm{m}^{-2}\right)\end{array}$} & \multicolumn{3}{|c|}{$\begin{array}{l}\text { Liquid } \gamma \text { components } \\
\text { for 3-L method }\left(\mathrm{mJ} \mathrm{m}^{-2}\right)\end{array}$} \\
\hline & & $\gamma^{d}$ & $\gamma^{n d}$ & $\gamma^{L W}$ & $\gamma^{+}$ & $\gamma^{-}$ \\
\hline w & $72.8 \pm 0.0^{a}$ & $21.8 \pm 0.7^{\mathrm{a}}$ & $51.0 \pm 0.7^{\mathrm{a}}$ & $21.8^{\mathrm{C}}$ & $25.50^{c}$ & $25.50^{c}$ \\
\hline$G$ & $63.7 \pm 0.4^{b}$ & $33.6 \pm 0.3^{b}$ & $30.1 \pm 0.4^{b}$ & $33.6 \pm 0.3^{d}$ & $8.41 \pm 3.02^{d}$ & $31.16 \pm 14.23^{d}$ \\
\hline DM & $50.8 \pm 0.0^{a}$ & $49.0 \pm 0.5^{a}$ & $1.8 \pm 0.5^{a}$ & $50.8 \pm 0.0^{d}$ & $0.56 \pm 0.50^{d}$ & $0.00 \pm 0.00^{d}$ \\
\hline
\end{tabular}

TABLE 1 | Total surface free energy or surface tension $\left(\gamma_{I}\right)$ and its components (measured at $20^{\circ} \mathrm{C}$ ) of water (W), Glycerol (G), and diiodomethane (DM).

For calculations following the GM and HM methods (dispersive $\left(\gamma^{d}\right)$ and non-dispersive $\left(\gamma^{\text {nd }}\right)$ components) and for the 3-L method (Lifshitz-van der Waals ( $\left.\gamma^{L W}\right)$ and acid-base $\left(\gamma^{A B}\right.$; $\gamma^{+}$and $\gamma^{-}$) components). Data are means $\pm S D$.

a Mean values calculated from Fowkes (1964), Owens and Wendt (1969), Wu (1971, 1982) and Jañczuk and Białlopiotrowicz (1989).

b Mean values calculated from Fowkes (1964), Dann (1970), Panzer (1973), Wu (1971, 1982), Jañczuk and Chibowski (1983) and Jañczuk et al. (1993).

${ }^{c}$ Reference values taken by Van Oss et al. (1987).

d Mean values calculated from van Oss (1994) and Jañczuk et al. (1993, 1999). 
Where, $\gamma_{l}^{n d}$ is the non-dispersive component of the liquid and $\gamma_{s}^{\text {nd }}$ is the non-dispersive component of the solid.

Equation (3) is known as the Geometric mean, SFE calculation method, termed hereafter GM method.

\section{Harmonic Mean Method}

$\mathrm{Wu}$ (1971) proposed an alternative equation, based on the reciprocal mean and force additivity, which once applied to Young's equation for two liquids results in:

$$
4\left(\frac{\gamma_{s}^{d} \gamma_{l}^{d}}{\gamma_{s}^{d}+\gamma_{l}^{d}}+\frac{\gamma_{s}^{n d} \gamma_{l}^{n d}}{\gamma_{s}^{n d}+\gamma_{l}^{n d}}\right)=\gamma_{l}(1+\cos \theta)
$$

Equation (4) is known as the Harmonic mean, SFE calculation method, termed hereafter HM method.

\section{Three-liquids Method}

According to the Lifshitz-van der Waals-acid-base method, or van Oss, Good, and Chaudhury method (Van Oss et al., 1986, $1987,1988) \gamma$ can be divided into the following components:

$$
\gamma_{i}=\gamma_{i}^{L W}+\gamma_{i}^{A B}=\gamma_{i}^{L W}+2 \sqrt{\gamma_{i}^{+} \gamma_{i}^{-}}
$$

where $i$ denotes either the solid or the liquid phase and the acid-base component $\left(\gamma^{A B}\right)$ breaks down into the electron-donor $\left(\gamma^{-}\right)$and the electron-acceptor $\left(\gamma^{+}\right)$interactions. For a solidliquid system, the following expression is given (Van Oss et al., 1987, 1988):

$$
2\left(\gamma_{s}^{L W} \gamma_{l}^{L W}\right)^{1 / 2}+2\left(\gamma_{s}^{+} \gamma_{l}^{-}\right)^{1 / 2}+2\left(\gamma_{s}^{-} \gamma_{l}^{+}\right)^{1 / 2}=\gamma_{l}(1+\cos \theta)
$$

where the 3 surface tension components (i.e., $\gamma_{s}^{L W}, \gamma_{s}^{+}$and $\gamma_{s}^{-}$) together with the SFE of the solid measured $\left(\gamma_{s}\right)$ can be obtained. This SFE calculation procedure is termed hereafter 3-L method.

\section{Solubility Parameter Calculations}

From the total surface tension and surface tension components estimated by the methods described above, the solubility parameter $(\delta)$ of plant surfaces was calculated using the following relation (Khayet et al., 2002):

$$
\delta=\left(e_{c}\right)^{1 / 2}
$$

where $e_{c}\left(\mathrm{MJ} \mathrm{m}^{-3}\right)$ is the cohesive energy density, which is related to $\gamma_{s}\left(\mathrm{~mJ} \mathrm{~m}^{-2}\right)$ as follows:

$$
e_{c}=\left(\frac{\gamma_{\mathrm{s}}}{0.75}\right)^{3 / 2}
$$

\section{Results}

\section{Liquid Surface Tension Mean Values}

The average values of the total surface tension $\gamma_{l}$ and its components for the 3 liquids measured (W, G, and DM) were calculated together with their standard deviation using the data reported in the literature. For the GM and the HM, 2-liquids methods, the surface tension components are $\gamma_{l}^{d}$ and $\gamma_{l}^{\text {nd }}$ while for the 3-L method they are $\gamma^{L W}, \gamma^{-}$, and $\gamma^{+}$(Table 1). The estimation of $\gamma_{l}^{d}$ either via measuring contact angles on to a known solid or by liquid-liquid interfacial tension measurements may differ (Jañczuk et al., 1993). This was chiefly noticeable in the case of $\mathrm{G}$.

Beginning with the 2-liquid approaches (i.e., the GM and HM methods), the mean $\gamma_{l}, \gamma_{l}^{d}$, and $\gamma_{l}^{\text {nd }}$ values of W and DM were obtained from: Fowkes (1964), Owens and Wendt (1969), Wu (1971, 1982), and Jañczuk and Białlopiotrowicz (1989). Glycerol surface values are the average of the results reported by Fowkes (1964), Dann (1970), Panzer (1973), Wu (1971, 1982), Jañczuk and Chibowski (1983) and Jañczuk et al. (1993).

The Liftshizt-van der Waals and acid-base components (including $\gamma^{-}$and $\gamma^{+}$) of $\mathrm{W}$ were taken as reference by Van Oss et al. (1987). The $\gamma^{L W}, \gamma^{-}$and $\gamma^{+}$mean values of $\mathrm{G}$ and DM were calculated from the data reported by van Oss (1994) and Jañczuk et al. (1993, 1999). For G, it is remarkable the high degree of dispersion of the $\gamma^{+}$and chiefly the $\gamma^{-}$components (see Table 1).

\section{Plant Surface Topography}

The adaxial leaf surface of red ironbark and blue gum eucalypt, and abaxial leaf side of holm oak were found to have a high degree of roughness (Figures 1A-C). This is due to the presence of milimetric trichomes on to the lower leaf side of holm-oak, wax nano-tubes on the surface of blue gum eucalypt leaves, and wax platelets and a complex micro-topography provided by the epidermal cells of red ironbark leaves. By contrast, the upper leaf surface of rubber tree and Chilean myrtle is rather flat alike that of pepper fruit (Figures 1D-F).

\section{Contact Angles}

The contact angle values of W, G, and DM with the surface of the examined plant materials are shown in Table 2. In Figure 2 the contact angles of water (W), glycerol (G), and diiodomethane (DM) with one of the rough (blue gum leaf) and smooth (pepper fruit) surfaces analyzed are shown as an example. The structural complexity observed in the adaxial surfaces of red ironbark, blue gum eucalypt, and abaxial holm-oak leaf surfaces led to very high contact angles with polar liquids (i.e., W and G; Figures $\mathbf{2 A , B}$ ). While the blue gum eucalypt leaf is wettable $\left(\theta<90^{\circ}\right)$ for DM (Figure 2C), which suggests the occurrence of chemical interactions between such liquid and epicuticular wax nanotubes, the surfaces of red ironbark and holm oak leaves are unwettable $\left(\theta>90^{\circ}\right)$ for such largely apolar liquid.

Pepper fruit and rubber gum leaf surfaces are wetted by $\mathrm{W}$, G and DM drops (see Figures 2D-F as an example). The surface of Chilean myrtle is however unwettable for $\mathrm{W}$ and $\mathrm{G}$, but the contact angles measured (approximately $100^{\circ}$ ) are well below those determined for red ironbark, blue gum eucalypt, and holm oak leaves.

\section{Surface Free Energy Calculation by Different Procedures}

The SFE results calculated for the mean surface tension values (Table 1) and contact angles (Table 2) according to the 3-L, GM 


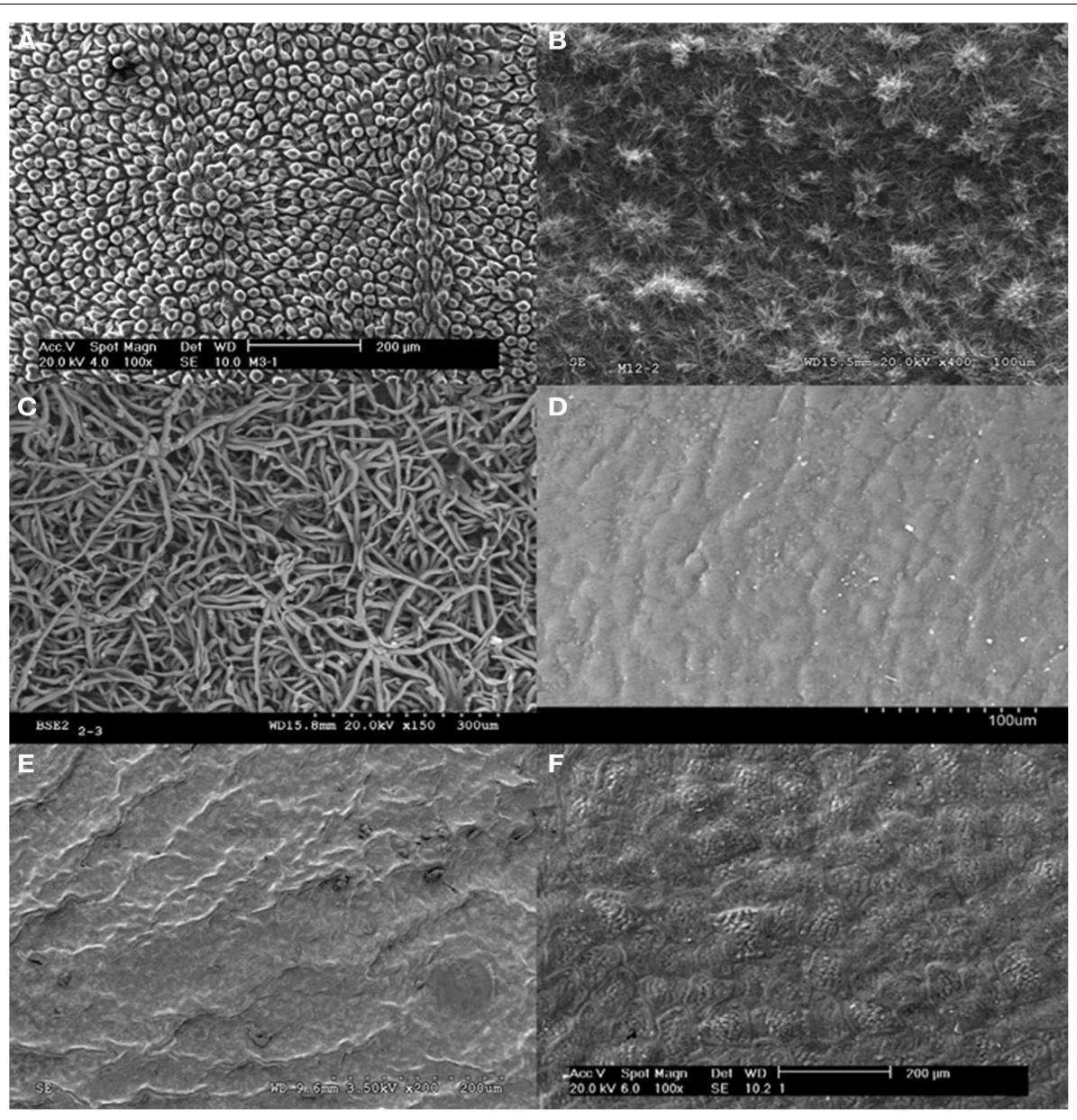

FIGURE 1 | Plant surfaces analysed. (A) Upper leaf side of red ironbark (major micro- and nano roughness), (B) upper leaf side of juvenile blue gum (major micro- and nano roughness conferred by wax nano-tubes), (C) lower leaf side of holm oak (great micro-roughness conferred by the hairs/trichomes), (D) upper leaf side of rubber tree (rather smooth), (E) upper leaf side of Chilean myrtle (rather smooth), and (F) pepper fruit surface (rather smooth).
TABLE 2 | Contact angles of water $\left(\theta_{w}\right)$, glycerol $\left(\theta_{g}\right)$ and diiodomethane $\left(\theta_{d}\right)$ on the upper side of red ironbark, blue gum eucalypt, rubber tree and Chilean myrtle leaves, lower side of holm oak leaves, and pepper fruit surfaces.

\begin{tabular}{lrcr}
\hline Sample & $\boldsymbol{\theta}_{\boldsymbol{w}}\left(^{\circ}\right)$ & $\boldsymbol{\boldsymbol { \theta } _ { \boldsymbol { g } }}\left(^{\circ}\right)$ & $\boldsymbol{\theta}_{\boldsymbol{d}}\left(^{\circ}\right)$ \\
\hline Red ironbark & $138.29 \pm 4.39$ & $144.68 \pm 7.25$ & $126.07 \pm 3.87$ \\
Blue gum eucalypt & $142.58 \pm 6.70$ & $136.52 \pm 11.15$ & $84.03 \pm 6.99$ \\
Holm oak & $134.77 \pm 4.85$ & $139.08 \pm 4.55$ & $123.09 \pm 3.04$ \\
Rubber tree & $83.75 \pm 8.19$ & $82.03 \pm 7.51$ & $59.17 \pm 3.94$ \\
Chilean myrtle & $100.48 \pm 4.97$ & $98.24 \pm 6.49$ & $60.01 \pm 2.65$ \\
Pepper fruit & $83.39 \pm 4.72$ & $68.57 \pm 9.23$ & $60.80 \pm 6.24$ \\
\hline
\end{tabular}

or HM methods are grouped in Tables 3-8 for the different plant materials assessed. It must be highlighted that the 3 model smooth surfaces analyzed had lower contact angles chiefly with polar liquids and higher SFE values, which were within a similar range (approximately from 31 to $38 \mathrm{~mJ} \mathrm{~m}^{-2}$ ) at least when determined by the 3-L method. The rough surfaces examined had very high contact angles with polar liquids (see Figure 2 as an example) and $S F E$ varying from 5 to $19 \mathrm{~mJ} \mathrm{~m}^{-2}$ when calculated by the 3-Liquids method.

Since we understand that the characterization of surfaces by measuring contact angles of 3 liquids with different dispersive and non-dispersive contributions (W, G, and DM) provides more information than comparing pairs of liquids (W-DM, G-DM, or W-G), we analyzed the SFE results taking the 3-L method as reference. Furthermore, since we used average surface tension and surface tension component values, which are comparable for all the SFE estimation approaches employed, it could be expected that, for the same plant material, at least some of the SFE results derived from pairs of liquids would be within the range obtained by the 3-L method. Based on the developed theory (Equations 3-6) it would be desirable that data estimated for $\gamma_{s}^{\mathrm{LW}}$ and $\gamma_{s}^{\mathrm{d}}, \gamma_{s}^{\mathrm{AB}}$ and $\gamma_{s}^{\text {nd }}$, and also $\gamma_{s}$ and $\delta$ would be comparable among methods. For assessing the potential similarity between the results derived from 2 and 3 liquid calculation procedures, 
the percentage deviation from de 3 - $\mathrm{L}$ method is provided in Tables 3-8.

The upper leaf surface of red iron bark, which is quite rough (Figure 1A), was found to have quite low total SFE $(6.42 \mathrm{~mJ}$ $\left.\mathrm{m}^{-2}\right)$ and $\delta\left(5.01 \mathrm{MJ}^{1 / 2} \mathrm{~m}^{-3 / 2}\right)$ values which are however within the range determined for holm oak abaxial surfaces. The $\gamma_{s}^{\mathrm{LW}}$ is lower than the $\gamma_{s}{ }^{\mathrm{AB}}$ component chiefly due to the high $\gamma_{s}^{-}$value (Table 3). While selecting W-DM data and calculating the SFE by the HM method, $\gamma_{s}$ and $\delta$ values do not deviate so much for the 3-L method results ( -9.0 and $7.0 \%$ deviation, respectively). However, this approach led to a major over-estimation of the $\gamma_{s}^{\mathrm{LW}}$ component. The remaining GM and HM results have a high degree of dispersion when compared to the 3-L method.

The adaxial side of juvenile blue gum leaves has also a high degree of roughness (Figure 1B). The total SFE calculated by

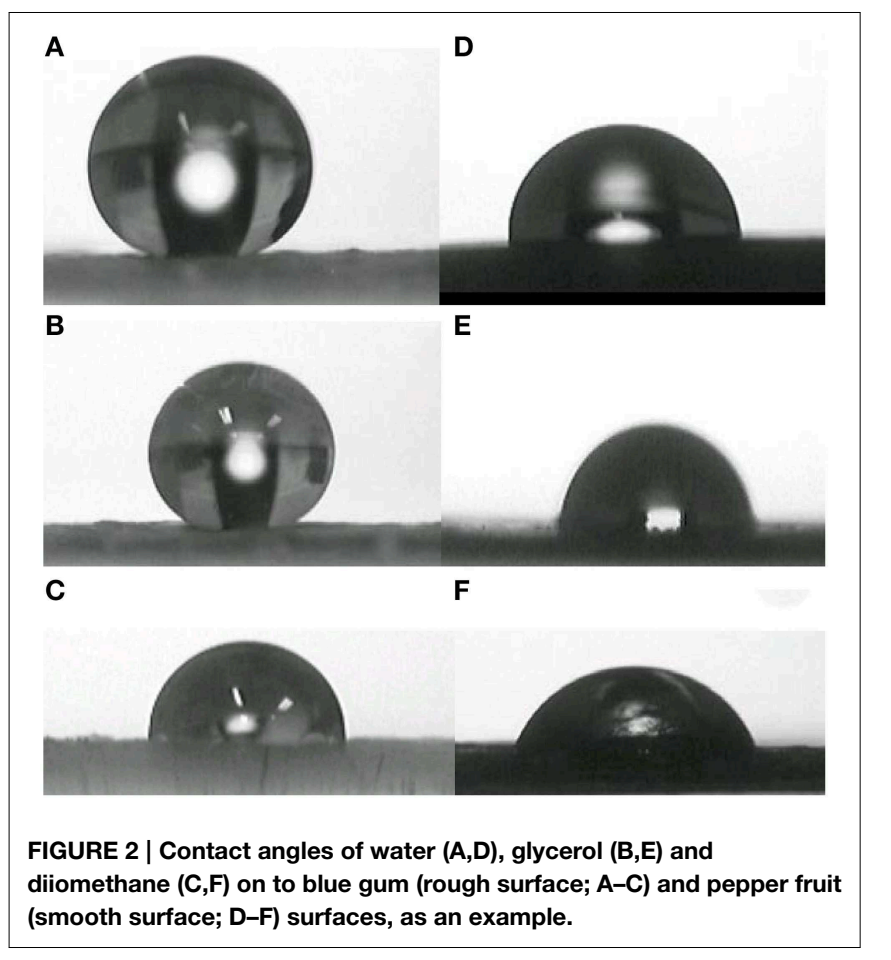

the 3-L method is $19.07 \mathrm{~mJ} \mathrm{~m}^{-2}$, principally due to a large $\gamma_{s}^{\mathrm{LW}}$ compared to the $\gamma_{s}{ }^{\mathrm{AB}}$ component (Table 4). The SFE and $\delta$ results obtained with $\mathrm{W}-\mathrm{DM}$ and the GM method had the lowest deviation (from 12 to $27 \%$ for all parameters) from the $3-\mathrm{L}$ method. The remaining results obtained with the GM and HM methods led to significant SFE and $\delta$ under or over-estimations in relation to the $3-\mathrm{L}$ method values.

The lower leaf surface of holm oak has a high degree of microroughness provided by pubescence (Figure 1C), and low total SFE $\left(5.97 \mathrm{~mJ} \mathrm{~m}{ }^{-2}\right)$ and $\delta\left(4.74 \mathrm{MJ}^{1 / 2} \mathrm{~m}^{-3 / 2}\right)$ values (Table 5). When considering W-DM data and using the HM method, $\gamma_{s}$ and $\delta$ values presented a low deviation from the $3-\mathrm{L}$ method (11.1 and 8.2\%, respectively). However, the HM approach led to a major over-estimation of $\gamma_{s}{ }^{\mathrm{d}}(189.1 \%)$ and an underestimation $(-80.0 \%)$ of the $\gamma_{s}^{\text {nd }}$ components, as also recorded for red ironbark (Table 3). The remaining GM and HM values significantly deviated from the results obtained using the $3-\mathrm{L}$ method (Table 5).

The upper leaf surface of rubber tree is rather smooth (Figure 1D) and has a higher total SFE (principally associated with a high $\gamma_{s}^{\mathrm{LW}}$ and a significant $\gamma_{s}^{-}$component) and $\delta$ value $\left(31.76 \mathrm{~mJ} \mathrm{~m}^{-2}\right.$ and $16.60 \mathrm{MJ}^{1 / 2} \mathrm{~m}^{-3 / 2}$, respectively). The lowest deviation from the results obtained by the 3-L method was obtained for W-DM and the GM approach (from 2.0 to $3.9 \%$ deviation for $\gamma_{s}^{\mathrm{d}}, \gamma_{s}$, and $\delta$ ), which however led to a $24.3 \%$ underestimation of $\gamma_{s}^{\text {nd }}$ (Table 6). Using W-DM and G-DM pairs and calculating $\gamma_{s}$ by the GM or HM approaches led to results with low deviations from the 3-L method, with the exception of the $\gamma_{s}^{\text {nd }}$ component which was under-estimated in the case of $\mathrm{W}-\mathrm{DM}$ and largely G-DM using the GM method (-24.3 and $-85.9 \%$, respectively), and G-DM calculated with the HM method (-60.5\% deviation).

The rather flat upper leaf surface of Chilean myrtle (Figure 1E) has the highest total SFE (chiefly due to a high $\gamma_{s}^{\mathrm{LW}}$ and a significant $\gamma_{s}^{-}$component) and $\delta$ values of all the plant materials analyzed $\left(38.12 \mathrm{~mJ} \mathrm{~m}^{-2}\right.$ and $19.04 \mathrm{MJ}^{1 / 2} \mathrm{~m}^{-3 / 2}$, respectively). The lowest $\gamma_{s}^{\mathrm{d}}, \gamma_{s}$, and $\delta$ deviations from the 3$\mathrm{L}$ method were obtained for G-DM using the GM method, followed by W-DM calculated by the HM and GM approaches (Table 7). However, all of these results based on pairs of liquids

TABLE 3 | Surface free energy $\left(\gamma_{s}\right)$, solubility parameter $(\delta)$, surface free energycomponents, i.e., Lifschitz-van der Waals or dispersive component $\left(\gamma_{s}^{\mathrm{LW}}\right.$ or d) acid-base or non-dispersive component $\left(\gamma_{s}^{\mathrm{AB}}\right.$ or nd), electron-donor $\left(\gamma_{s}^{-}\right)$and the electron-acceptor $\left(\gamma_{s}^{+}\right)$components), of adaxial red ironbark leaf surfaces calculated by the 3-liquids (3-L), geometric mean (GM) and harmonic mean (HM) methods.

\begin{tabular}{|c|c|c|c|c|c|c|c|}
\hline Method & Test liquids & $\gamma_{s}^{\mathrm{LW}}$ or $\mathrm{d}\left(\mathrm{mJ} \mathrm{m}^{-2}\right)$ & $\gamma_{s}^{-}\left(\mathrm{mJ} \mathrm{m}^{-2}\right)$ & $\gamma_{s}^{+}\left(\mathrm{mJ} \mathrm{m}^{-2}\right)$ & $\gamma_{\mathrm{S}}^{\mathrm{AB} \text { or } \mathrm{nd}}\left(\mathrm{mJ} \mathrm{m}^{-2}\right)$ & $\gamma_{s}\left(\mathrm{~mJ} \mathrm{~m}^{-2}\right)$ & $\delta\left(\mathbf{M J}^{1 / 2} \mathrm{~m}^{-3 / 2}\right)$ \\
\hline 3-L & W, G, DM & 1.60 & 3.67 & 1.58 & 4.82 & 6.42 & 5.01 \\
\hline GM & W, DM & 2.02 (26.3\%) & - & - & $0.13(-97.3 \%)$ & $2.16(-66.4 \%)$ & $2.21(-55.9 \%)$ \\
\hline GM & G, DM & $2.61(63.1 \%)$ & - & - & $0.41(-91.5 \%)$ & $3.01(-53.1 \%)$ & $2.84(-43.3 \%)$ \\
\hline GM & W, G & $0.31(-80.6 \%)$ & - & - & $0.86(-82.2 \%)$ & $1.17(-81.8 \%)$ & $1.40(-72.1 \%)$ \\
\hline $\mathrm{HM}$ & W, DM & 5.83 (264.4\%) & - & - & $0.02(-99.6 \%)$ & $5.84(-9.0 \%)$ & $4.66(-7.0 \%)$ \\
\hline $\mathrm{HM}$ & G, DM & * & - & - & * & * & * \\
\hline $\mathrm{HM}$ & W, G & * & - & - & * & * & * \\
\hline
\end{tabular}

The deviation from the $3-L$ method is indicated in brackets.

Values cannot be calculated. 
TABLE 4 | Surface free energy $\left(\gamma_{s}\right)$ and its components $\left(\gamma_{s}^{\mathrm{LW}}\right.$ or d $\gamma_{s}^{\mathrm{AB}}$ or nd, $\gamma_{s}^{+}$and $\left.\gamma_{s}^{-}\right)$, and solubility parameter $(\delta)$ of adaxial blue gum eucalypt leaf surfaces calculated by the $3-\mathrm{L}$, GM, and HM methods.

\begin{tabular}{|c|c|c|c|c|c|c|c|}
\hline Method & Test liquids & 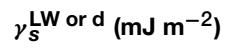 & $\gamma_{s}^{-}\left(\mathrm{mJ} \mathrm{m}^{-2}\right)$ & $\gamma_{s}^{+}\left(\mathrm{mJ} \mathrm{m}^{-2}\right)$ & $\gamma_{s}^{A B}$ or nd $\left(m J m^{-2}\right)$ & $\gamma_{s}\left(\mathrm{~mJ} \mathrm{~m}^{-2}\right)$ & $\delta\left(\mathbf{M J ~ J}^{1 / 2} \mathbf{m}^{-3 / 2}\right)$ \\
\hline 3-L & W, G, DM & 14.87 & 0.55 & 7.98 & 4.22 & 19.07 & 11.32 \\
\hline GM & W, DM & $18.92(27.2 \%)$ & - & - & $3.22(-23.7 \%)$ & 22.14 (16.1\%) & 12.67 (11.9\%) \\
\hline GM & $W, G$ & $1.82(-87.8 \%)$ & - & - & $0.03(-99.3 \%)$ & $1.85(-90.3 \%)$ & $1.97(-82.6 \%)$ \\
\hline $\mathrm{HM}$ & W, DM & $9.02(-39.3 \%)$ & - & - & $-2.50(-159.2 \%)$ & $6.51(-65.9 \%)$ & $5.06(-55.3 \%)$ \\
\hline
\end{tabular}

The deviation from the $3-L$ method is indicated in brackets.

TABLE 5 | Surface free energy $\left(\gamma_{s}\right)$ and its components $\left(\gamma_{s}^{\mathrm{LW}}\right.$ or d $\gamma_{s}^{\mathrm{AB}}$ or nd, $\gamma_{s}^{+}$and $\left.\gamma_{s}^{-}\right)$, and solubility parameter ( $\delta$ ) of abaxial holm oak leaf surfaces calculated by the 3-L, GM and HM methods.

\begin{tabular}{|c|c|c|c|c|c|c|c|}
\hline Method & Test liquids & $\gamma_{s}^{\mathrm{LW} \text { or } \mathrm{d}}\left(\mathrm{mJ} \mathrm{m}^{-2}\right)$ & $\gamma_{s}^{-}\left(\mathbf{m J ~ m}^{-2}\right)$ & $\gamma_{s}^{+}\left(\mathrm{mJ} \mathrm{m}^{-2}\right)$ & $\gamma_{s}^{\mathrm{AB} \text { or } \mathrm{nd}}\left(\mathrm{mJ} \mathrm{m}^{-2}\right)$ & $\gamma_{s}\left(\mathrm{~mJ} \mathrm{~m}^{-2}\right)$ & $\delta\left(\mathrm{MJ}^{1 / 2} \mathrm{~m}^{-3 / 2}\right)$ \\
\hline GM & W, DM & 2.41 (19.3\%) & - & - & $0.24(-93.9 \%)$ & $2.65(-55.6 \%)$ & $2.58(-45.6 \%)$ \\
\hline GM & $W, G$ & $0.05(-97.5 \%)$ & - & - & $1.86(-52.9 \%)$ & $1.91(-68.0 \%)$ & $2.01(-57.6 \%)$ \\
\hline $\mathrm{HM}$ & W, DM & 5.84 (189.1\%) & - & - & $0.79(-80.0 \%)$ & $6.63(11.1 \%)$ & $5.13(8.2 \%)$ \\
\hline
\end{tabular}

The deviation from the $3-L$ method is indicated in brackets.

values cannot be calculated.

TABLE 6 | Surface free energy $\left(\gamma_{s}\right)$ and its components $\left(\gamma_{s}^{\mathrm{LW}}\right.$ or d $\gamma_{s}^{\mathrm{AB}}$ or nd, $\gamma_{s}^{+}$and $\left.\gamma_{s}^{-}\right)$, and solubility parameter $(\delta)$ of adaxial rubber tree leaf surfaces calculated by the 3-L, GM and HM methods.

\begin{tabular}{|c|c|c|c|c|c|c|c|}
\hline Method & Test liquids & 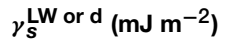 & $\gamma_{s}^{-}\left(\mathrm{mJ} \mathrm{m}^{-2}\right)$ & $\gamma_{s}^{+}\left(\mathrm{mJ} \mathrm{m}^{-2}\right)$ & $\gamma_{s}^{A B}$ or nd $\left(m^{\prime} m^{-2}\right)$ & $\gamma_{s}\left(\mathrm{~mJ} \mathrm{~m}^{-2}\right)$ & $\delta\left(\mathrm{MJ}^{1 / 2} \mathrm{~m}^{-3 / 2}\right)$ \\
\hline 3-L & W, G, DM & 24.41 & 18.35 & 0.74 & 7.36 & 31.76 & 16.60 \\
\hline GM & W, DM & $25.36(3.9 \%)$ & - & - & $5.57(-24.3 \%)$ & $30.93(-2.6 \%)$ & $16.27(-2.0 \%)$ \\
\hline GM & W, G & $5.66(-76.8 \%)$ & - & - & $16.78(128.0 \%)$ & $22.44(-29.3 \%)$ & $12.79(-23.0 \%)$ \\
\hline $\mathrm{HM}$ & W, DM & $27.70(13.5 \%)$ & - & - & $9.46(28.5 \%)$ & $37.16(17.0 \%)$ & $18.68(12.5 \%)$ \\
\hline
\end{tabular}

The deviation from the $3-L$ method is indicated in brackets.

led to a major under-estimation of the $\gamma_{s}{ }^{\text {nd }}$ component (ranging from -80 to $-96 \%$ deviations).

Finally, the rather smooth pepper fruit surface (Figure 1F) has also high $\gamma_{s}$ (principally associated with a large $\gamma_{s}^{\mathrm{LW}}$ component) and $\delta$ values $\left(31.66 \mathrm{~mJ} \mathrm{~m}{ }^{-2}\right.$ and $16.56 \mathrm{M}^{1 / 2} \mathrm{~m}^{-3 / 2}$, respectively). Using W-DM contact angles following the GM approach led to $\gamma_{s}$ and $\delta$ data with low deviations from the 3-L method (with $3.1-7.4 \%$ under-estimations for $\gamma_{s}^{\mathrm{d}}, \gamma_{s}$ and $\delta$ and $11.4 \%$ overestimation for $\gamma_{s}^{\text {nd }}$; Table 8). For W-G, and the GM method, $\gamma_{s}$ and $\delta$ results slightly deviated from the 3-L method (8-18\% overestimations for $\gamma_{s}^{\mathrm{d}}, \gamma_{s}$ and $\delta$ and $23.2 \%$ under-estimation of $\gamma_{s}^{\text {nd }}$ ). Using G-DM and W-DM with the GM method, and even W-DM, G-DM and W-G with the HM approach also led to $\gamma_{s}^{\mathrm{d}}, \gamma_{s}$ and $\delta$ values with low deviations. However, such 2-liquid combinations led to a major over-estimation of the $\gamma_{s}^{\text {nd }}$ component (from 40 to $100 \%$ ) as compared to the results obtained by the 3-L method.

Calculations by the HM method led to some negative results for blue gum and holm oak leaves or to no results in the case of G-DM and G-W combinations for red iron bark and also for GDM calculations for Chilean myrtle and holm oak. These results have no physical significance and are related to mathematical constraints associated with HM method equations.

\section{Discussion}

The SFE of a material is a fundamental property that determines its surface and interfacial performance in processes like wetting and adhesion (Adão et al., 1999). Despite its importance for 


\begin{tabular}{|c|c|c|c|c|c|c|c|}
\hline Method & Test liquids & $\gamma_{s}^{\mathrm{LW}}$ or d $\left(\mathrm{mJ} \mathrm{m}^{-2}\right)$ & $\gamma_{s}^{-}\left(\mathrm{mJ} \mathrm{m}^{-2}\right)$ & $\gamma_{s}^{+}\left(\mathrm{mJ} \mathrm{m}^{-2}\right)$ & $\gamma_{s}^{\mathrm{AB} \text { or } \mathrm{nd}}\left(\mathrm{mJ} \mathrm{m}^{-2}\right)$ & $\gamma_{s}\left(\mathrm{~mJ} \mathrm{~m}^{-2}\right)$ & $\delta\left(\mathrm{MJ}^{1 / 2} \mathrm{~m}^{-3 / 2}\right)$ \\
\hline $3-L$ & W, G, DM & 25.02 & 10.70 & 4.01 & 13.10 & 38.12 & 19.04 \\
\hline GM & W, DM & $28.19(12.7 \%)$ & - & - & $0.49(-96.3 \%)$ & $28.67(-24.8 \%)$ & $15.38(-19.2 \%)$ \\
\hline GM & G, DM & $31.68(26.6 \%)$ & - & - & $0.94(-92.8 \%)$ & $32.62(-14.4 \%)$ & $16.94(-11.0 \%)$ \\
\hline GM & W, G & $4.04(-83.9 \%)$ & - & - & $8.15(-37.5 \%)$ & $12.19(-68.0 \%)$ & $8.09(-57.5 \%)$ \\
\hline $\mathrm{HM}$ & W, DM & $28.38(13.4 \%)$ & - & - & $2.69(-79.5 \%)$ & $31.07(-18.5 \%)$ & $16.33(-14.2 \%)$ \\
\hline $\mathrm{HM}$ & $\mathrm{G}, \mathrm{DM}$ & * & - & - & * & * & * \\
\hline $\mathrm{HM}$ & W, G & $4.51(-82.0 \%)$ & - & - & 14.27 (8.9\%) & $18.77(-50.8 \%)$ & $11.19(-41.2 \%)$ \\
\hline
\end{tabular}

The deviation from the $3-L$ method is indicated in brackets.

*Values cannot be calculated.

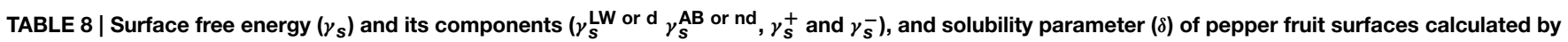
the 3-L, GM, and HM methods.

\begin{tabular}{|c|c|c|c|c|c|c|c|}
\hline Method & Test liquids & $\gamma_{s}^{\mathrm{LW}}$ or $\mathrm{d}\left(\mathrm{mJ} \mathrm{m}^{-2}\right)$ & $\gamma_{s}^{-}\left(\mathrm{mJ} \mathrm{m}^{-2}\right)$ & $\gamma_{s}^{+}\left(\mathrm{mJ} \mathrm{m}^{-2}\right)$ & $\gamma_{s}^{\mathrm{AB} \text { or } \mathrm{nd}}\left(\mathrm{mJ} \mathrm{m}^{-2}\right)$ & $\gamma_{s}\left(\mathrm{~mJ} \mathrm{~m}^{-2}\right)$ & $\delta\left(\mathrm{MJ}^{1 / 2} \mathrm{~m}^{-3 / 2}\right)$ \\
\hline 3-L & W, G, DM & 26.22 & 3.00 & 2.47 & 5.44 & 31.66 & 16.56 \\
\hline GM & W, DM & $24.28(-7.4 \%)$ & - & - & $6.06(11.4 \%)$ & $30.33(-4.2 \%)$ & $16.04(-3.1 \%)$ \\
\hline GM & G, DM & $23.67(-9.7 \%)$ & - & - & $7.75(42.5 \%)$ & $31.42(-0.8 \%)$ & $16.47(-0.5 \%)$ \\
\hline GM & W, G & $30.95(18.0 \%)$ & - & - & $4.18(-23.2 \%)$ & $35.14(11.0 \%)$ & $17.91(8.2 \%)$ \\
\hline $\mathrm{HM}$ & W, DM & $26.92(2.7 \%)$ & - & - & $9.84(80.9 \%)$ & $36.76(16.1 \%)$ & $18.52(11.8 \%)$ \\
\hline $\mathrm{HM}$ & $\mathrm{G}, \mathrm{DM}$ & $26.99(2.9 \%)$ & - & - & $8.73(60.5 \%)$ & $35.72(12.8 \%)$ & $18.13(9.5 \%)$ \\
\hline $\mathrm{HM}$ & $W, G$ & $22.91(-12.6 \%)$ & - & - & $11.11(104.2 \%)$ & $34.02(7.5 \%)$ & $17.48(5.6 \%)$ \\
\hline
\end{tabular}

The deviation from the 3- $L$ method is indicated in brackets.

characterizing contact phenomena related to plant surfaces, such as the interaction of plant organs with surface deposited water (Brewer et al., 1991) or insects (Prüm et al., 2012), only few studies considered this parameter in a plant science context so far (Gorb et al., 2004; Fernández et al., 2011, 2014a,b; Khayet and Fernández, 2012; Wang et al., 2014). The estimation of the SFE and solubility parameter of plant materials may be, for example, useful for predicting water-plant surface interactions and the potential of plant organs to absorb water and agrochemical solutions (Fernández et al., 2011, 2014a,b).

Several SFE calculation methods were introduced during the last 50 years and the drawbacks of estimating SFE based on contact angle measurements by different procedures have been highlighted in some reports (e.g., Kwok and Neumann, 1999; Chibowski and Perea-Carpio, 2002; Della Volpe et al., 2004), which may be minimized if carefully considering the procedures, at least for comparing between different plant materials, which is the aim of this study.

Surface roughness can affect liquid contact angles and it is a matter of interest for many researchers dealing with solid-liquid interactions (Bhushan and Nosonovsky, 2010). According to the models of Wenzel (1936) and Cassie and Baxter (1944), there are two regimes of wetting of a rough surface: a homogeneous regime with a 2-phase solid-liquid interface, and a non-homogeneous regime with a 3-phase solid-water-air interface (with air pockets between the solid and the liquid).

When revising the existing SFE-related multi-disciplinary literature, we recognized that an array of test liquids with different total surface tension and surface tension components were available. We focused on water, glycerol and diiodomethane which are commonly used due to their distinct dispersive and non-dispersive components (e.g., Adão et al., 1999; Jañczuk et al., 1999). It is worth highlighting that for test liquids, we recognized that different surface tension values were used by authors when calculating SFE for instance, by the GM vs. the HM approach and that the method of determination of the dispersive component (e.g., with contact angles or interfacial tension measurements) may also have an influence on the surface tension values of liquids. Additionally, we actually noticed that the calculation methods were extremely sensitive to slight surface tension and surface tension component value modifications. Therefore, we decided to work with average surface tension and surface tension component values, which may be comparable among different SFE calculation methods as shown in Table 1. This choice enabled us to trust that for the same plant surface, the potential SFE differences are not due to the different surface tension values of test liquids, but rather to the particular calculation method in combination with the surface features of the materials analyzed. Thereby, we standardized the surface tension values of W, G and $\mathrm{DM}$ by using the mean values calculated after revising the exiting literature, and subsequently used them for estimating the SFE of plant materials.

Aware that any of the SFE calculation methods based on either 2 or 3 liquids analyzed produced certain SFE and SFE component values, we wondered if the results were meaningful and comparable between and within species. For verifying this 
aspect, 3 rough and 3 smother plant materials were selected as model species, and contact angles with W, G, and DM were carefully measured under similar conditions.

Since we understand that the characterization of a surface by measuring drops of 3 test liquids with different properties is more informative than using only 2 liquids having different dispersive and non-dispersive interactions, we took the results obtained using the 3-L method as reference and estimated the potential deviation of SFE, SFE components and solubility parameter $(\delta)$ values. This last parameter was theoretically calculated by Khayet and Fernández (2012) for model wax compounds, and provides insight into the combined effect of surface chemical composition (plant surfaces are generally covered with waxes having a theoretical $\delta$ ranging between 16 and $17 \mathrm{MJ}^{1 / 2} \mathrm{~m}^{-3 / 2}$ ) and roughness. Looking at the mean surface tension components shown in Table 1, it can be derived that in a decreasing order, $\mathrm{W}$ has the highest non-dispersive component, followed by $\mathrm{G}$ and DM. On the contrary, DM has the highest dispersive (apolar) component, followed by $\mathrm{G}$ and W. It is hence easy to understand that drops of such liquids may perform differently depending on the chemical and structural nature of every different surface, as observed in this study. While measuring contact angles of drops of 2 liquids may save time when determining SFE of samples either by the GM or HM methods, we must be sure that results are meaningful and comparable with those obtained by the $3-\mathrm{L}$ method.

We could not find a clear relationship between surface roughness and SFE calculation methods, since for example, for the blue gum eucalypt leaf which is quite rough, W-DM contact angles estimated by the GM method provided fair SFE and $\delta$ estimations. On the contrary, for the rather smooth Chilean myrtle leaf, none of the pairs of liquids combinations and 2-liquid calculation methods lead to values within the range obtained with the 3-L method, chiefly due to a severe under-estimation of $\gamma_{s}^{\text {nd }}$. Our observations agree with the comments of Kwok and Neumann (1999), who noted that "there are as yet no general criteria to answer the question of how smooth a solid surface has to be for surface roughness not to have an effect on the contact angle."

The combination W-DM calculated with the GM method provided fair SFE and $\delta$ results for rubber tree, blue gum leaves and pepper fruit. Most of the 2-liquid combinations and calculation methods generally led to $\gamma_{s}^{\text {nd }}$ under-estimations and sometimes $\gamma_{s}^{\mathrm{d}}$ over-estimations for red iron bark, holm oak and Chilean myrtle compared to the 3 - L results. The HM method generally led to the highest deviations from the $3-\mathrm{L}$ method as compared to the GM method. According to $\mathrm{Wu}$ $(1971,1982)$ the HM approach has been described to be suitable

\section{References}

Adão, M. H. V. C., Saramago, B. J. V., and Fernandes, A. C. (1999). Estimation of the surface properties of styrene-acrylonitrile random copolymers from contact angle measurements. J. Colloid Interface Sci. 217, 94-106. doi: 10.1006/jcis.1999.6279 for analysing surfaces with low SFE and not for applying it to systems involving phases with widely different polarizabilities. Limitations associated with the use of the HM method for assessing the SFE of surfaces having some degree of polarity have been reported earlier (e.g., Wu, 1971; Adão et al., 1999).

The results obtained for blue gum and holm oak leaves, and pepper fruit surfaces with the 3-L method and mean liquid surface tension values shown in Table 1, are within the range reported by Khayet and Fernández (2012) and Fernández et al. (2014a). The most remarkable difference is that we have considered the $\gamma_{l}^{+}$of DM, which may be crucial for surfaces having significant polar components as noted by Tretinnikov (2000). The $\delta$ empirically determined for the smooth rubber tree and pepper fruit surfaces are coincident with the theoretical values estimated by Khayet and Fernández (2012), hence indicating a negligible effect of surface roughness and the prevalence of chemical interactions between such plant materials and liquid drops. On the contrary, the lower $\delta$ values determined for the rough iron bark, holm oak and to a lower degree, blue gum leaves reflect a significant effect of surface micro- and or-nano-structure on plant surface-liquid interactions.

\section{Conclusions}

An analysis of the total surface tension and surface tension component values of test liquids reported in the literature led us to select the mean values for water (W), glycerol $(G)$, and diiodomethane $(\mathrm{DM})$, and enabled the comparison between different surface free energy calculation methods. Despite it would be less time-consuming to be able to measure only 2 liquids for characterizing plant surfaces of unknown physical and chemical properties, we gained evidence that it is not possible to a priori select a combination of 2 liquids and a suitable calculation method (GM or HM methods), which may provide results comparable to those obtained using the Lifshitz-van der Waals-acid-base method. We hence suggest the standard use of the gamma values calculated for W, G and DM (Table 1) and the $3-\mathrm{L}$ method for drawing coherent conclusions concerning the surface free energy of plant surfaces, related for instance, to different species, organs, developmental stages or growing conditions.

\section{Acknowledgments}

VF is supported by a Ramón y Cajal contract (MINECO, Spain), co-financed by the European Social Fund. Thanks to Ricardo Fernández for his technical support for the development of this study.

Barthlott, W., Neinhuis, C., Cutler, D., Ditsch, F., Meusel, I., Theisen, I., et al. (1998). Classification and terminology of plant epicuticular waxes. Bot. J. Linn. Soc. 126, 237-260. doi: 10.1111/j.1095-8339.1998.tb02529.x

Berry, Z. C., Hughes, N. M., and Smith, W. K. (2014). Cloud immersion: an important water source for spruce and fir saplings in the southern Appalachian Mountains. Oecologia 174, 319-326. doi: 10.1007/s00442-013-2770-0 
Bhushan, B., and Jung, Y. C. (2010). Natural and biomimetic artificial surfaces for superhydrophobicity, self- cleaning, low adhesion, and drag reduction. Prog. Mat. Sci. 56, 1-108. doi: 10.1016/j.pmatsci.2010.04.003

Bhushan, B., and Nosonovsky, M. (2010). The rose petal effect and the modes of superhydrophobicity. Philos. T. R. Soc. A 368, 4713-4728. doi: 10.1098/rsta.2010.0203

Brewer, C. A., and Nuñez, C. I. (2007). Patterns of leaf wettability along an extreme moisture gradient in western Patagonia, Argentina. Int. J. Plant Sci. 168, 555-562. doi: 10.1086/513468

Brewer, C. A., and Smith, W. K. (1997). Patterns of leaf surface wetness for montane and subalpine plants. Plant Cell Environ. 20, 1-11. doi: 10.1046/j.1365-3040.1997.d01-15.x

Brewer, C. A., Smith, W. K., and Vogelmann, T. C. (1991). Functional interaction between leaf trichomes, leaf wettability and the optical properties of water droplets. Plant Cell Environ. 14, 955-962. doi: 10.1111/j.13653040.1991.tb00965.x

Burkhardt, J., and Hunsche, M. (2013). "Breath figures" on leaf surfacesformation and effects of microscopic leaf wetness. Front. Plant Sci. 4:422. doi: 10.3389/fpls.2013.00422

Cassie, A., and Baxter, S. (1944). Wettability of porous surfaces. Trans. Faraday Soc. 40, 546-551. doi: 10.1039/tf9444000546

Chibowski, E., and Perea-Carpio, R. (2002). Problems of contact angle and solid surface free energy determination. Adv. Coll. Interface Sci. 98, 245-264. doi: 10.1016/S0001-8686(01)00097-5

Chibowski, E., and Staszczuk, P. (1988). Determination of surface free energy of kaolinite. Clays Clay Min. 36, 455-461. doi: 10.1346/CCMN.1988.0360511

Correia, N. T., Ramos, J. J. M., Saramago, B. J., and Calado, J. C. (1997). Estimation of the surface tension of a solid: application to a liquid crystalline polymer. J. Colloid Interface Sci. 189, 361-369. doi: 10.1006/jcis.1997.4857

Dann, J. R. (1970). Forces involved in the adhesive process: I. Critical surface tensions of polymeric solids as determined with polar liquids. J. Colloid Interface Sci. 32, 302-320. doi: 10.1016/0021-9797(70)90054-8

Della Volpe, C., Maniglio, D., Brugnara, M., Siboni, S., and Morra, M. (2004). The solid surface free energy calculation: I. In defense of the multicomponent approach. J. Colloid Interface Sci. 271, 434-453. doi: 10.1016/j.jcis.2003.09.049

Della Volpe, C., and Siboni, S. (1997). Some reflections on acid-base solid surface free energy theories. J. Colloid Interface Sci. 195, 121-136. doi: $10.1006 /$ jcis. 1997.5124

Dietz, J., Leuschner, C., Hölscher, D., and Kreilein, H. (2007). Vertical patterns and duration of surface wetness in an old-growth tropical montane forest, Indonesia. Flora 202, 111. doi: 10.1016/j.flora.2006.03.004

Eigenbrode, S. D., and Jetter, R. (2002). Attachment to plant surface waxes by an insect predator. Integr. Comp. Biol. 42, 1091-1099. doi: 10.1093/icb/42.6.1091

Eller, C. B., Lima, A. L., and Oliveira, R. S. (2013). Foliar uptake of fog water and transport belowground alleviates drought effects in the cloud forest tree species, Drimys brasiliensis (Winteraceae). New Phytol. 199, 151-162. doi: 10.1111/nph.12248

Fernández, V., and Brown, P. H. (2013). From plant surface to plant metabolism: the uncertain fate of foliar-applied nutrients. Front. Plant Sci. 4:289. doi: 10.3389/fpls.2013.00289

Fernández, V., and Eichert, T. (2009). Uptake of hydrophilic solutes through plant leaves: current state of knowledge and perspectives of foliar fertilization. Crit. Rev. Plant Sci. 28, 36-68. doi: 10.1080/07352680902743069

Fernández, V., Guzmán, P., Peirce, C. A. E., McBeath, T. M., Khayet, M., and McLaughlin, M. J. (2014b). Effect of wheat phosphorus status on leaf surface properties and permeability to foliar applied phosphorus. Plant Soil 384, 7-20. doi: 10.1007/s11104-014-2052-6

Fernández, V., Khayet, M., Montero-Prado, P., Heredia-Guerrero, J. A., Liakopoulos, G., Karabourniotis, G., et al. (2011). New insights into the properties of pubescent surfaces: peach fruit as a model. Plant Physiol. 156, 2098-2108. doi: 10.1104/pp.111.176305

Fernández, V., Sancho-Knapik, D., Guzmán, P., Peguero-Pina, J. J., Gil, L., Karabourniotis, G., et al. (2014a). Wettability, polarity and water absorption of holm oak leaves: effect of leaf side and age. Plant Physiol. 166, 168-180. doi: $10.1104 /$ pp.114.242040

Fowkes, F. M. (1962). Determination of interfacial tensions, contact angles, and dispersion forces in surfaces by assuming additivity of intermolecular interactions in surfaces. J. Phys. Chem. 66, 382-382. doi: 10.1021/j100808a524
Fowkes, F. M. (1964). Attractive forces at interfaces. Ind. Eng. Chem. 56, 40-52. doi: 10.1021/ie50660a008

Fox, H. W., and Zisman, W. A. (1950). The spreading of liquids on low energy surfaces. I. Polytetrafluoroethylene. J. Coll. Sci. 5, 514-531. doi: 10.1016/00958522(50)90044-4

Gindl, M., Sinn, G., Gindl, W., Reiterer, A., and Tschegg, S. (2001). A comparison of different methods to calculate the surface free energy of wood using contact angle measurements. Coll. Surf. A 181, 279-287. doi: 10.1016/S09277757(00)00795-0

Girifalco, L. A., and Good, R. J. (1957). A theory for the estimation of surface and interfacial energies. I. Derivation and application to interfacial tension. J. Phys. Chem. 61, 904-909. doi: 10.1021/j150553a013

Good, R. J. (1977). Surface free energy of solids and liquids: thermodynamics, molecular forces, and structure. J. Colloid Interface Sci. 59, 398-419. doi: 10.1016/0021-9797(77)90034-0

Gorb, E., Kastner, V., Peressadko, A., Arzt, E., Gaume, L., Rowe, N., et al. (2004). Structure and properties of the glandular surface in the digestive zone of the pitcher in the carnivorous plant Nepenthes ventrata and its role in insect trapping and retention. J. Exp. Biol. 207, 2947-2963. doi: 10.1242/jeb. 01128

Guzmán, P., Fernández, V., Graça, J., Cabral, V., Kayali, N., Khayet, M., et al. (2014). Chemical and structural analysis of Eucalyptus globulus and E. camaldulensis leaf cuticles: a lipidized cell wall region. Front. Plant Sci. 5:481. doi: 10.3389/fpls.2014.00481

Hanba, Y. T., Moriya, A., and Kimura, K. (2004). Effect of leaf surface wetness and wettability on photosynthesis in bean and pea. Plant Cell Environ. 27, 413-421. doi: 10.1046/j.1365-3040.2004.01154.x

Helmy, A. K., Ferreiro, E. A., and De Bussetti, S. G. (2004). The surface energy of kaolinite. Coll. Polym. Sci. 283, 225-228. doi: 10.1007/s00396-004-1150-z

Jañczuk, B., and Białlopiotrowicz, T. (1989). Surface free-energy components of liquids and low energy solids and contact angles. J. Colloid Interface Sci. 127, 189-204. doi: 10.1016/0021-9797(89)90019-2

Jañczuk, B., Białopiotrowicz, T., and Wójcik, W. (1989). The components of surface tension of liquids and their usefulness in determinations of surface free energy of solids. J. Colloid Interface Sci. 127, 59-66. doi: 10.1016/00219797(89)90007-6

Jañczuk, B., Białlopiotrowicz, T., and Zdziennicka, A. (1999). Some remarks on the components of the liquid surface free energy. J. Colloid Interface Sci. 211, 96-103. doi: 10.1006/jcis.1998.5990

Jañczuk, B., and Chibowski, E. (1983). Interpretation of contact angle in solid hydrocarbon-water system. J. Colloid Interface Sci. 95, 268-270. doi: 10.1016/0021-9797(83)90096-6

Jañczuk, B., Wójcik, W., and Zdziennicka, A. (1993). Determination of the components of the surface tension of some liquids from interfacial liquidliquid tension measurements. J. Colloid Interface Sci. 157, 384-393. doi: 10.1006/jcis.1993.1200

Javelle, M., Vernoud, V., Rogowsky, P. M., and Gwyneth, C. I. (2011). Epidermis: the formation and functions of a fundamental plant tissue. New Phytol. 189, 17-39. doi: 10.1111/j.1469-8137.2010.03514.x

Jeffree, C. E., Baker, E. A., and Holloway, P. J. (1975). Ultrastructure and recrystallization of plant epicuticular waxes. New Phytol. 75, 539-549. doi: 10.1111/j.1469-8137.1975.tb01417.x

Jetter, R., Kunst, L., and Samuels, A. L. (2006). “Composition of plant cuticular waxes," in Biology of the Plant Cuticle, Annual Plant Reviews, Vol. 23, eds M. Riederer and C. Müller (Oxford: Blackwell), 145-181.

Karabourniotis, G., and Bormann, J. F. (1999). Penetration of UV-A UV-B and blue light through the leaf trichome of two xeromorphic plants, olive and oak, measured by optical fibre microprobes. Physiol. Plantarum 105, 655-661. doi: 10.1034/j.1399-3054.1999.105409.x

Khayet, M., Chowdhury, G., and Matsuura, T. (2002). Surface modification of polyvinylidene fluoride pervaporation membranes. AIChE J. 48, 2833-2843. doi: 10.1002/aic.690481211

Khayet, M., Feng, C. Y., and Matsuura, T. (2003). Morphological study of fluorinated asymmetric polyetherimide ultrafiltration membranes by surface modifying macromolecules. J. Membr. Sci. 213, 159-180. doi: 10.1016/S03767388(02)00523-9

Khayet, M., and Fernández, V. (2012). Estimation of the solubility parameters of model plant surfaces and agrochemicals: a valuable tool for understanding 
plant surface interactions. Theor. Biol. Med. Model. 9, 45. doi: 10.1186/17424682-9-45

Khayet, M., Vazquez Alvarez, M., Khulbe, K. C., and Matsuura, T. (2007). Preferential surface segregation of homopolymer and copolymer blend films. Surf. Sci. 601, 885-895. doi: 10.1016/j.susc.2006.11.024

Koch, K., and Barthlott, W. (2009). Superhydrophobic and super- hydrophilic plant surfaces: an inspiration for biomimetic materials. Philos T. R. Soc. A 367, 1487-1509. doi: 10.1098/rsta.2009.0022

Konrad, W., Ebner, M., Traiser, C., and Roth-Nebelsick, A. (2012). Leaf surface wettability and implications for drop shedding and evaporation from forest canopies. Pure Appl. Geophys. 169, 835-845. doi: 10.1007/s00024-011-0330-2

Kwok, D. Y., Li, D., and Neumann, A. W. (1994). Evaluation of the Lifshitz-van der Waals/acid-base approach to determine interfacial tensions. Langmuir 10, 1323-1328. doi: 10.1021/la00016a057

Kwok, D. Y., and Neumann, A. W. (1999). Contact angle measurement and contact angle interpretation. Adv. Coll. Interface Sci. 81, 167-249. doi: 10.1016/S00018686(98)00087-6

Limm, E. B., and Dawson, T. E. (2010). Polystichum munitum (Dryopteridaceae) varies geographically in its capacity to absorb fog water by foliar uptake within the redwood forest ecosystem. Am. J. Bot. 97, 1121-1128. doi: 10.3732/ajb.1000081

Morra, M. (1996). Some reflection on the evaluation of the Lewis acid-base properties of polymer surfaces by wetting measurements. J. Colloid Interface Sci. 182, 312-314. doi: 10.1006/jcis.1996.0469

Oliveira, R. S., Dawson, T. E., and Burgess, S. O. (2005). Evidence for direct water absorption by the shoot of the dessication-tolerant plant Vellozia flavicans in the savannas of central Brazil. J. Tropical Ecol. 21, 585-588. doi: $10.1017 /$ S0266467405002658

Owens, D. K., and Wendt, R. C. (1969). Estimation of the surface free energy of polymers. J. Appl. Polym. Sci. 13, 1741-1747. doi: 10.1002/app.1969.070130815

Panzer, J. (1973). Components of solid surface free energy from wetting measurements. J. Colloid Interface Sci. 44, 142-161. doi: 10.1016/00219797(73)90201-4

Prüm, B., Seidel, R., Bohn, H. F., and Speck, T. (2012). Plant surfaces with cuticular folds are slippery for beetles. J. R. Soc. Interface 9, 127-135. doi: 10.1098/rsif.2011.0202

Reicosky, D. A., and Hanover, J. W. (1978). Physiological effects of surface waxes. Plant Physiol. 62, 101-104. doi: 10.1104/pp.62.1.101

Riederer, M. (2006). "Introduction: biology of the plant cuticle," in Biology of the Plant Cuticle, Annual Plant Reviews, Vol. 23, eds M. Riederer and C. Müller (Oxford: Blackwell), 1-10.

Riederer, M., and Schreiber, L. (2001). Protecting against water loss: analysis of the barrier properties of plant cuticles. J. Exp. Bot. 52, 2023-2032. doi: 10.1093/jexbot/52.363.2023

Rosado, B. H., and Holder, C. D. (2013). The significance of leaf water repellency in ecohydrological research: a review. Ecohydrology 6, 150-161. doi: $10.1002 /$ eco. 1340

Roth-Nebelsick, A., Ebner, M., Miranda, T., Gottschalk, V., Voigt, D., Gorb, S., et al. (2012). Leaf surface structures enable the endemic Namib desert grass Stipagrostis sabulicola to irrigate itself with fog water. J. R. Soc. Interface 9, 1965-1974. doi: 10.1098/rsif.2011.0847
Saa, S., Olivos-Del Rio, A., Castro, S., and Brown, P. H. (2015). Foliar application of microbial and plant based biostimulants increases growth and potassium uptake in almond (Prunus dulcis [Mill.] D. A. Webb). Front. Plant Sci. 6:87. doi: 10.3389/fpls.2015.00087

Serrano, M., Coluccia, F., Torres, M., L'Haridon, F., and Métraux, J. P. (2014). The cuticle and plant defense to pathogens. Front. Plant Sci. 5:274. doi: $10.3389 /$ fpls.2014.00274

Shepherd, T., and Wynne Griffiths, D. (2006). The effects of stress on plant cuticular waxes. New Phytol. 171, 469-499. doi: 10.1111/j.14698137.2006.01826.x

Tretinnikov, O. N. (2000). On neglecting the polar nature of halogenated hydrocarbons in the surface energy determination of polar solids from contact angle measurements. J. Colloid Interface Sci. 229, 644-647. doi: 10.1006/jcis.2000.7024

Urrego-Pereira, Y. F., Martínez-Cob, A., Fernández, V., and Cavero, J. (2013). Daytime sprinkler irrigation effects on net photosynthesis of maize and alfalfa. Agron. J. 105, 1515-1528. doi: 10.2134/agronj2013.0119

van Oss, C. J. (1994). Interfacial Forces in Aqueous Media. New York, NY: Marcel Dekker, 440.

van Oss, C. J., Chaudhury, M. K., and Good, R. J. (1987). Monopolar surfaces. Adv. Colloid Interface Sci. 28, 35-64. doi: 10.1016/0001-8686(87) 80008-8

van Oss, C. J., Chaudhury, M. K., and Good, R. J. (1988). Interfacial Lifshitz-van der Waals and polar interactions in macroscopic systems. Chem. Rev. 88, 927-941. doi: 10.1021/cr00088a006

Van Oss, C. J., Good, R. J., and Chaudhury, M. K. (1986). The role of van der Waals forces and hydrogen bonds in "hydrophobic interactions" between biopolymers and low energy surfaces. J. Colloid Interface Sci. 111, 378-390. doi: 10.1016/0021-9797(86)90041-X

Wang, H., Shi, H., Li, Y., and Wang, Y. (2014). The effects of leaf roughness, surface free energy and work of Adhesion on leaf water drop adhesion. PLoS ONE 9:e107062. doi: 10.1371/journal.pone.0107062

Wenzel, R. N. (1936). Resistance of solid surfaces to wetting by water. Ind. Eng. Chem. 28, 988-994. doi: 10.1021/ie50320a024

Wu, S. (1971). Calculation of interfacial tension in polymer systems. J. Polym. Sci. C, 34, 193. doi: 10.1002/polc.5070340105

Wu, S. (Ed). (1982). "Contact angles of liquids on solid polymers," in Polymer Interface and Adhesion, (New York, NY: Marcel Dekker), 67-168.

Young, T. (1805). An essay on the cohesion of fluids. Philos. Trans. R. Soc. London 95, 65-87. doi: 10.1098/rstl.1805.0005

Conflict of Interest Statement: The authors declare that the research was conducted in the absence of any commercial or financial relationships that could be construed as a potential conflict of interest.

Copyright (C) 2015 Fernández and Khayet. This is an open-access article distributed under the terms of the Creative Commons Attribution License (CC BY). The use, distribution or reproduction in other forums is permitted, provided the original author(s) or licensor are credited and that the original publication in this journal is cited, in accordance with accepted academic practice. No use, distribution or reproduction is permitted which does not comply with these terms. 